\title{
POR QUE A CIÊNCIA NÃO RESOLVE NOSSOS PROBLEMAS?
}

\section{Daniel DURANTE}

* Doutor em Lógica e Filosofia da Ciência, Engenheiro de Computação pela Universidade Estadual de Campinas (UNICAMP) e Professor associado do Departamento de Filosofia da Universidade Federal do Rio Grande do Norte (UFRN), em Natal, Brasil. E-mail: durante@ufrnet.br.

Artigo submetido em maio/2015 e aceito em setembro/2015

DOI: http://dx.doi.org/10.15628/dialektike.2015.3049

\section{RESUMO}

Além de responder à pergunta título, pretende-se também apresentar as linhas gerais de um caminho que vem sendo proposto por alguns pensadores sobre de que maneira a ciência poderia se modificar de modo a que pudéssemos utilizá-la para resolver nossos principais problemas. Para tanto iniciaremos explicitando o que consideramos as características mais fundamentais da racionalidade científica hegemônica, a saber: o atomismo e o método axiomático. Em seguida, apresentamos alguns conhecidos problemas das ciências, evidenciando suas relações com estas características fundamentais. Tais problemas são tanto epistemológicos e metodológicos, internos ao próprio conhecimento, quanto éticos, relacionados às suas consequências. Em seguida,
\end{abstract}

indicamos como a forte interconexão destes dois tipos de problemas pode ser compreendida quando entendemos a ciência de modo instrumental como uma resposta ao interesse de previsão para manipulação e controle. Por fim, partindo do reconhecimento do caráter contingente e socialmente construído do conhecimento científico, inclusive de suas características fundamentais, respondemos à questão título e apontamos, ainda de modo incipiente, algumas possibilidades de modificações metodológicas que têm sido propostas nos últimos anos. Em especial, apresentamos as que foram rotuladas de complexidade e a transdisciplinaridade, indicando algumas questões e possíveis linhas de pesquisa que estas abordagens suscitam.

PALAVRAS-CHAVE: Método científico. Complexidade. Transdisciplinaridade. Atomismo.

Método axiomático. Construtivismo.

\section{ABSTRACT}

Besides answering the title question, my purpose with this essay is to present the outlines of an alternative way that has been proposed by some thinkers, on how our conception of science could be modified, so that it would help us to solve our main problems. In order to do that, I begin explaining what I see as the most fundamental characteristics of hegemonic scientific rationality, namely atomism and the axiomatic method. Then I present some known issues of this conception of science, showing its relations with these fundamental characteristics. Such problems are as much epistemological and methodological, closed to the knowledge itself, as much as they are ethical and related to its consequences. Then I set that the strong interconnection of these two types of problems can be better explained when we understand science in a instrumental way, as a response to a former interest for manipulation and control. Finally, based on the recognition of this contingent and socially constructed character of scientific knowledge, I answer the title question and indicate some possible methodological modifications to scientific practice that have been proposed in recent years. In particular, I present those that were labeled of complexity, transdisciplinarity, and methodological pluralism, indicating some issues and possible lines of research that these approaches raise.

KEYWORDS: Scientific method. Complexity. Transdisciplinarity. Atomism. Axiomatic method. 


\section{DURANTE, Daniel (2015)}

Constructivism.

\section{INTRODUÇÃO}

A ciência nos ajuda a encontrar cura para doenças, a erradicar pragas, a construir máquinas maravilhosas, que nos fazem voar, nos levaram à Lua, que nos colocam em contato comunicativo instantâneo com qualquer outra pessoa em qualquer lugar do mundo, através de textos, sons e imagens. A ciência nos informa sobre as origens e desenvolvimento do universo, de nosso planeta, da vida, de nossa constituição biológica e psicológica, nos ajuda a explicar o comportamento do mundo material e até a entender o funcionamento de nossos próprios corpos e mentes.

Quando pensamos sobre todas as maravilhas fantásticas que a ciência nos ajudou a conquistar, em tudo o que sabemos e conseguimos fazer por causa dela, quando comparamos nosso entendimento e atuação no mundo com o que tínhamos há algumas centenas de anos, fica muito difícil de entender por que todo este desenvolvimento não nos ajudou a resolver nossos principais problemas. Diferentemente do que sonhou o filósofo Francis Bacon em sua utopia da Nova Atlântida, o desenvolvimento científico não nos levou a um mundo de perfeição, harmonia e bem estar generalizado. Mesmo com tudo o que passamos a saber através da ciência, com toda a ampliação de nossa capacidade de atuação no mundo que a tecnologia científica nos deu, não temos sido capazes de resolver os principais problemas que sempre assolaram a humanidade.

E mais ainda, a mesma ciência que nos ajudou a domesticar a energia nuclear, também nos ajudou a produzir armas capazes de destruir completamente o nosso planeta, muitas vezes até. Os mesmos avanços científicos que desvendam o código genético de nossa espécie, simultaneamente e de modo inextricável, também produzem a possibilidade de segregação e controle do indivíduo através da informação genética. A mesma ciência que compreende cada vez mais a fundo a natureza, contribui para a devastação ambiental do planeta. A mesma ciência que nos ajuda a produzir riqueza, bem-estar e poder, também contribui para a manutenção das desigualdades sociais, propiciando novas formas de controle, dominação e segregação. Mesmo com todo o desenvolvimento científico que conquistamos, vivemos em um mundo onde fome, miséria, ignorância e violência são problemas tão reais e 


\section{DURANTE, Daniel (2015)}

urgentes quanto o eram há 500 anos. A ciência não resolve nossos principais problemas. Por que?

Além de dar uma resposta a esta questão, a ambiciosa (possivelmente pretensiosa) proposta deste ensaio é também a de apontar um caminho para a ciência, um caminho em que os conhecimentos científicos não sejam tão alienados dos nossos problemas reais. Tal caminho envolve alternativas metodológicas heterodoxas que tocam inclusive nas bases lógicas da racionalidade científica. Obviamente não sou eu quem, de modo isolado, propõe este caminho. Ele tem sido aberto pelos trabalhos de inúmeros intelectuais de variadas vertentes, desde o filósofo e historiador da ciência norte americano Thomas Kuhn, até os filósofos/antropólogos/sociólogos franceses Edgar Morin e Bruno Latour, além da física e ativista política indiana Vandana Shiva, do físico romeno Bassarab Nicolescu, entre outros e, principalmente, do filósofo australiano Hugh Lacey, ${ }^{1}$ que com seu minucioso trabalho de exposição das parcialidades éticas e epistêmicas da metodologia científica hegemônica e sua proposta de adoção de um pluralismo metodológico na ciência, tem chamado a atenção tanto para a inabilidade atual da ciência para resolver os nossos principais problemas, como também para a possibilidade de que novas diretrizes metodológicas para a investigação científica possam dar conta desta tarefa, ou seja, possam fazer com que as realizações da ciência sejam, também, passos importantes na direção da solução deste problemas.

Iniciaremos nosso ensaio com uma reflexão que pode ser encarada como uma reconstituição histórico-conceitual da metodologia científica hegemônica atual, no que concerne aos seus aspectos mais centrais e racionais. Em seguida apresentaremos algumas questões problemáticas que esta metodologia nos legou. Faremos isso de modo resumido e com o mínimo possível de detalhes técnicos disciplinares, privilegiando esclarecer em que medida estes problemas metodológicos e epistemológicos da ciência representam desafios para a própria racionalidade científica. Por outro lado, há a questão título deste ensaio: por que a ciência não resolve nossos principais problemas? Esta é uma questão sobre a relação entre a ciência e a ética, direciona-se à aplicação da ciência e ao modo como o conhecimento científico afeta ou não as nossas vidas. Vamos, de modo ainda mais breve, apenas relembrar não apenas a inabilidade da ciência em resolver os nossos principais problemas, como também a sua vinculação com o agravamento dos problemas existentes e até com a criação de novos.

\footnotetext{
${ }^{1}$ Como principais referências destes desenvolvimentos podemos citar Kuhn (2000), Morin (2005, 2001, 1999b, 1990, 1999a), Latour (2000,2001), Shiva (2001,2003), Nicolescu (1999) e Lacey (1998,2004, 2010).
} 


\section{DURANTE, Daniel (2015)}

Tradicionalmente, estes dois tipos de problemas, os epistemológicos/metodológicos e os éticos, não são tratados em conjunto. Costumam ser vistos como sendo de naturezas diferentes, tendo causas diferentes e, portanto, exigindo abordagens diferentes. Quanto aos problemas do primeiro tipo, os metodológicos, são os próprios cientistas, principalmente nos momentos de controvérsia, e os filósofos da ciência com pendor mais disciplinar, que costumam dedicar-se a eles. Exemplos de conhecidas reflexões sobre alguns destes problemas são Heisemberg(1995) e Suppes(1969). Quanto aos problemas do segundo tipo, os éticos, eles costumam ser tratados pelos intelectuais mais ligados aos Estudos Sociais da Ciência, através de uma chave interpretativa que quase sempre os desvincula do conteúdo da ciência, afastando-os, por isto, das questões epistemológicas e metodológicas do conhecimento científico. Como exemplos destas abordagens temos Merton (1979), Ben-David \& Sullivan (1975). Mas há também alguns poucos autores que, independentemente de dirigirem-se aos problemas específicos aos quais aludiremos, reconhecem uma ligação forte entre a epistemologia e a ética da ciência e buscam um tratamento mais integrado destas dimensões. Alguns exemplos são Morin (1990) e Lacey (2004).

Em nosso esforço de tentar explicar por que a ciência não resolve nossos principais problemas, vinculamo-nos a esta terceira tradição de abordagens unificadoras. Se bem sucedidos, pretendemos contribuir para o esclarecimento do nexo que liga os problemas epistemológicos aos problemas éticos da ciência. Tal nexo será buscado nas diretrizes mais gerais da racionalidade científica. Nossa ideia é mostrar que algumas das diretrizes mais fundamentais da razão científica estão na raiz dos dois tipos de problemas, epistemológicos e éticos, que a ciência enfrenta. E que, por mais radical que a proposta pareça, será possível viabilizar soluções para estes problemas apenas se admitirmos e propusermos mudanças para os fundamentos da própria racionalidade científica.

Partiremos do reconhecimento de que a ciência, enquanto atividade humana é como é porque nós, durante séculos, a produzimos assim, sem qualquer imposição necessária da natureza ou do entendimento humano sobre o método científico. No entanto, ainda que socialmente construído, o conhecimento científico e seu método adquiriram maturidade, organização e homogeneidade suficientes a ponto de podermos apontar certas características tão fundamentais que, presentes em praticamente todas as suas expressões, poderíamos 


\section{DURANTE, Daniel (2015)}

chamar de universais. $^{2}$ Assim, partindo do reconhecimento do caráter contingente e socialmente construído do conhecimento científico, ao invés de focalizarmos nossa análise nos aspectos que propiciaram esta construção, vamos analisar o produto acabado desta obra em suas características mais gerais. Juntamente, esboçaremos uma crítica ética, já corrente, a respeito das consequências muitas vezes nocivas do conhecimento científico. Nestes dois casos, o que interessa é mostrar a relação de dependência destes problemas (epistemológicos e éticos) com a estrutura racional mais geral que dá forma ao conhecimento científico.

Antes, no entanto, cabe uma justificativa quanto à abordagem escolhida. O principal e talvez mais atacável pressuposto de que partimos é a admissão de que o conhecimento científico, mesmo em suas características mais fundamentais, é uma construção histórica que não deve necessariamente sua forma e método nem à natureza nem tampouco à estrutura última de nossa racionalidade. Tal pressuposto, no entanto, não é novidade. Há muito vem sendo assumido em várias frentes intelectuais como decorrência de uma abordagem epistemológica específica que se convencionou chamar de construtivismo.

De maneira bastante simplificada poderíamos definir o construtivismo, conforme o estamos considerando aqui, como uma epistemologia (teoria sobre o conhecimento) que não busca justificar-se através de ontologia (teoria sobre a realidade), mas atribui ao conhecimento um caráter de reorganização do sujeito, de adequação dos projetos do sujeito às restrições por ele experimentadas. Parte-se de um abandono da pretensão de descrever objetivamente a realidade, admitindo que qualquer descrição depende do sujeito que a produz. Para o construtivismo só é possível descrever a realidade enquanto experiência, a partir do ponto de vista de um observador (indivíduo ou grupo). Não é a estrutura da realidade, mas os projetos e interesses subjetivos deste observador que determinam de modo mais fundamental a forma de conhecer. Assim, as diferentes descrições da realidade são entendidas como construções cuja finalidade principal é dar sentido aos nossos projetos subjetivos. Nesta perspectiva, a ciência moderna seria uma resposta a determinado projeto. Sua forma de conhecer (metodologia) não se justificaria através de uma concepção sobre a realidade última à nossa volta (ontologia), mas a partir dos projetos e interesses que a inspiram. ${ }^{3}$

\footnotetext{
${ }^{2} \mathrm{O}$ termo universal, portanto, não deve ser entendido como referência a todo conhecimento científico possível, mas apenas ao conhecimento científico que historicamente temos produzido.

${ }^{3}$ Não há acordo na literatura quanto à definição rigorosa de construtivismo. Diferentes autores, tanto no campo da filosofia quanto nos estudos da cultura e da ciência, atribuem significados diversos ao termo (Hess, 1997, pp. 34-37) e (Hacking, 2001). Na abordagem que adotamos, o fundamental é frisar que não se trata de negar que haja realidade objetiva, reduzindo-a a uma construção subjetiva. Admitimos e experimentamos a objetividade da realidade através das inúmeras restrições que ela nos impõe a cada instante. No entanto, o conhecimento em
} 


\section{DURANTE, Daniel (2015)}

Se pode não haver razão filosófica incontestável para assumirmos esta perspectiva, há, no caso específico da ciência, ao menos uma razão histórica: mais de quatrocentos anos de ciência moderna nos ensinaram que a conexão entre o conhecimento científico e a realidade é problemática. As inúmeras reviravoltas e revisões das disciplinas científicas nos mostraram que é ingenuidade pretender uma ligação direta entre enunciados teóricos, dados factuais e mundo. Mas se não há esta ligação direta, se o conhecimento científico não é a descrição exata da realidade, então o que é o conhecimento científico? O que obtemos através dele? Por que o continuamos produzindo? Uma resposta construtivista possível a estas perguntas é bem simples: continuamos a fazer ciência simplesmente porque ela funciona. E funcionar significa nada mais do que atender a um interesse, a um projeto. Meu carro funciona porque atende aos meus interesses de locomoção, não porque seja uma máquina perfeita. A ciência funciona porque atende a certos interesses específicos, não porque produza uma descrição perfeita da realidade. Sua estrutura racional e diretrizes metodológicas mais gerais não são ferramentas que eliminam toda a subjetividade do conhecimento. São apenas ferramentas que respondem satisfatoriamente aos interesses subjetivos que a motivam.

Se antes a ciência defendia que a terra era o centro do universo, com o sol e as estrelas girando em nosso redor, e hoje afirma que nós que giramos em torno de um pequeno sol em uma das inúmeras espirais de uma dentre incontáveis galáxias, é porque existe algo mais resistente que a própria realidade nas descrições científicas. Algo que se mantém a despeito de todo o resto: um interesse. É esta nossa primeira aposta, e é a partir dela que iniciamos nossas reflexões. Se vamos criticar a forma mais geral do conhecimento científico e sugerir-lhe acréscimos, o fazemos amparados neste ponto de partida.

\section{DEMÓCRITO: O ATOMISMO GREGO E A SEPARAÇÃO ENTRE SUJEITO E OBJETO}

Nosso primeiro passo é uma busca, nos rastros da história do pensamento ocidental, por aquelas características que podem ser consideradas as constituintes mais fundamentais da racionalidade científica. Voltemos, pois, à Grécia antiga. No que tange à matéria, herdamos de Leucipo e Demócrito, filósofos atomistas pré-socráticos, nossa concepção mais geral. Para

geral e o conhecimento científico em particular, antes de serem uma descrição independente e neutra da realidade, representariam uma adequação de nossos projetos e interesses a estas restrições. São eles, nossos projetos e interesses, que determinam a forma de encarar as restrições que experimentamos e, portanto, determinam a forma de conhecer. Não o contrário.

Dialektiké. Ano 2, v. 2, out 2015, p. 03-37 | Revista de Filosofia 


\section{DURANTE, Daniel (2015)}

eles, tudo quanto existe é constituído de átomos, elementos simples, indivisíveis e permanentes, que representam os "tijolos" do universo. Os átomos foram uma das respostas à difícil tarefa a que se lançaram os primeiros filósofos, de tentar conciliar a permanência e a mudança, a geração e a corrupção que percebiam na natureza. Para Demócrito, as substâncias do universo são compostas por infinitos átomos de tipos distintos. As substâncias permanecem inalteradas enquanto as combinações de átomos que as formam se mantém. Quando, por algum motivo, os átomos se recombinam, as substâncias modificam-se. Permanência e mudança são, pois, explicadas através de combinações temporárias destes elementos permanentes. Os diversos tipos de átomos se diferenciam pela forma, tamanho e peso, sendo estas as características determinantes a guiar as suas possíveis combinações e recombinações. Encontra-se na doxografia de Simplício uma bela descrição do atomismo de Demócrito, que mostra quanto suas ideias acerca do universo são, na essência, as mesmas que a ciência de hoje persegue.

Demócrito julga que a natureza das coisas eternas são pequenas substâncias infinitas em grande quantidade. Para estas admite um outro lugar infinito em grandeza. E chama o lugar com estes nomes de vazio, de nada, de infinito e cada uma das substâncias com os nomes de algo, de sólido e de ser. E julga que as substâncias são tão pequenas que fogem às nossas percepções. E lhes são inerentes formas de toda espécie, figuras de toda espécie, e diferenças em grandeza. Destas, pois, como de elementos, engendra e combina todos os volumes visíveis e perceptíveis. E estas se agitam e são arrebatadas no vazio por causa da semelhança e das outras diferenças mencionadas; e, arrebatadas, tombam-se e se enlaçam num entrelaçamento tal que faz com que elas se toquem e estejam próximas umas das outras [...]. E a causa de se coordenarem as substâncias umas com as outras, até certo ponto, ele atribui aos ajustes e correspondências dos corpos. Pois alguns deles são oblíquos, outros em forma de anzol, ocos, curvos, e mais outros de inúmeras diferenças. Julga, portanto, que se mantêm a si mesmas e se coordenam até que alguma mais forte por uma necessidade surgindo do ambiente as agite $\mathrm{e}$ disperse. E afirma que a geração e a separação que lhe é contrária se processa não apenas com animais mas também com plantas, com mundos e, em suma, com todos os corpos sensíveis. (Souza, 1996, p.260)

Dentre as inúmeras outras cosmologias que os gregos nos legaram, o atomismo enquadrou os esforços da ciência moderna, que nos levaram à molécula, ao átomo, aos prótons e elétrons, e finalmente à inúmera variedade de partículas subatômicas. Tais esforços são tentativas de encontrar e isolar estes "tijolos" dos quais todos os "corpos sensíveis" são construídos. A ideia fundamental de Demócrito permanece na base das atuais descrições científicas do universo. 
Mas uma tal ontologia exige de Demócrito uma teoria do conhecimento coerente. Uma vez que são os fenômenos atômicos que constituem e explicam a realidade, e estes átomos são a nós imperceptíveis, então existe uma diferença entre o que percebemos e as explicações que normalmente damos aos fenômenos, relativamente ao que realmente existe e ao que realmente explica os fenômenos. A este respeito, temos três importantes fragmentos (Souza, 1996, p.266):

1. "É preciso que o homem aprenda segundo a regra que diz o seguinte: Ele está afastado da realidade".

2. "Por convenção existe o doce e por convenção o amargo, por convenção o quente, por convenção o frio, por convenção a cor; na realidade, porém, átomos e vazio".

3. "Há duas espécies de conhecimento, um genuíno, outro obscuro. Ao conhecimento obscuro pertencem, no seu conjunto, vista, audição, olfato, paladar e tato. O conhecimento genuíno, porém, está separado daquele. Quando o obscuro não pode ver com maior minúcia, nem sentir cheiro e sabor, nem perceber pelo tato, mas é preciso procurar mais finamente, então apresenta-se o genuíno, que possui um órgão de conhecimento mais fino".

Novamente, as ideias de Demócrito antecipam a ciência moderna. Percebemos aqui dois dos seus principais pressupostos: a separação entre sujeito e objeto (estamos afastados da realidade), e o ideal de objetividade científica, pois o conhecimento que se apresenta através de nossos sentidos, através de características do sujeito e de como ele é afetado pelos fenômenos, é "obscuro". O conhecimento "genuíno" se atinge por outro modo de conhecer, mais fino. O próprio Demócrito já nos ensinava que a ontologia atomista leva a uma epistemologia da separação entre sujeito e objeto e, portanto, à busca do conhecimento objetivo, aquele que descreve os fatos do mundo através de suas próprias propriedades e não de como nós, sujeitos, somos afetados por estes fatos. Ao comprar o atomismo de Demócrito, a ciência moderna levou junto o objetivismo.

\section{EUCLIDES INSPIRA DESCARTES: MÉTODO CIENTÍFICO COMO MÉTODO AXIOMÁTICO}

Descartes, quase dois mil anos depois de Demócrito, quando sistematizou as linhas gerais do método científico moderno, tinha como pressupostos esta separação entre sujeito e objeto e o ideal de objetividade do conhecimento. Descartes sintetizou seu método através de quatro postulados básicos, que descreveu em primeira pessoa: 
O primeiro era o de jamais acolher alguma coisa como verdadeira que eu não conhecesse evidentemente como tal; isto é, de evitar cuidadosamente a precipitação e a prevenção, e de nada incluir em meus juízos que não se apresentasse tão clara e tão distintamente a meu espírito, que eu não tivesse nenhuma ocasião de pô-lo em dúvida.

O segundo, o de dividir cada uma das dificuldades que eu examinasse em tantas parcelas quantas possíveis e quantas necessárias fossem para melhor resolvê-las.

O terceiro, o de conduzir por ordem meus pensamentos, começando pelos objetos mais simples e mais fáceis de conhecer para subir, pouco a pouco, como por degraus, até o conhecimento dos mais compostos, e supondo mesmo uma ordem entre os que não se precedem naturalmente uns aos outros.

E o último, o de fazer em toda parte enumerações tão completas e revisões tão gerais, que eu tivesse a certeza de nada omitir.

Essas longas cadeias de razões, todas simples e fáceis, de que os geômetras costumam servir-se para chegar às suas mais difíceis demonstrações, haviam-me dado ocasião de imaginar que todas as coisas possíveis de cair sob o conhecimento dos homens seguem-se umas às outras da mesma maneira. (Descartes, 1996, pp.78-79)

Percebe-se, no primeiro princípio do método cartesiano, que a medida da verdade são as ideias claras e distintas. Mas como atingir uma ideia clara e distinta? Como vencer a complexidade da realidade em busca da clareza e da distinção? De acordo com o segundo princípio acima, devemos dividir e separar a realidade em tantas parcelas quantas possíveis e necessárias para o melhor entendimento. O pensamento é então ordenado, começando dos objetos mais simples, mais "claros", reconstruindo os objetos complexos, através destes simples e de suas relações (terceiro princípio). É o método dos geômetras que deve ser aplicado para obter o conhecimento de todas as coisas. Mas qual é este método dos geômetras ao qual Descartes se refere? É o método axiomático, também desenvolvido pelos gregos antigos, e que foi sistematizado, por volta do ano $300 \mathrm{AC}$, na famosa obra Os Elementos, de Euclides.

Euclides, para tratar da geometria, o estudo quantitativo das formas e relações espaciais, começou por identificar um número mínimo de conceitos (elementos), com os quais seria possível construir e descrever todas as figuras e relações da geometria. Assim, ele definiu ponto, reta e plano. Com estes três elementos como matéria-prima, propôs cinco postulados, seus axiomas, proposições que considerou verdadeiras por serem claras e evidentes, a partir das definições dos três conceitos. ${ }^{4}$ Combinando e relacionando as cinco

\footnotetext{
${ }^{4}$ Os cinco axiomas propostos por Euclides são os seguintes: (1) Um segmento de reta pode ser desenhado unindo-se quaisquer dois pontos. (2) Qualquer segmento de reta pode ser estendido indefinidamente em uma reta. (3) Dado um segmento de reta, um círculo pode ser desenhado tendo o segmento como raio e um de seus
} 


\section{DURANTE, Daniel (2015)}

proposições verdadeiras iniciais, os cinco axiomas, tirou algumas conclusões imediatas e adicionou-as ao conjunto de verdades. Operando desta maneira, foi aumentando o conjunto de proposições verdadeiras, sempre acrescentando uma nova proposição a este conjunto apenas quando esta fosse uma consequência clara e evidente de proposições que ele já havia demonstrado serem verdadeiras. Com este método, Euclides demonstrou todos os teoremas da geometria conhecidos pelos gregos, dos mais simples aos mais complexos, e criou uma das mais sólidas obras científicas de todos os tempos, que permaneceu como uma espécie de bíblia da geometria por mais de dois mil anos (Hofstadter, 1989, p.88). É este o método dos geômetras, o método axiomático, e é este método que Descartes tomou como modelo para o conhecimento em geral e que está nas bases do modo de explicação científica mais aceito e que até hoje utilizamos.

Não se trata de exigir axiomatização formal, no sentido em que a lógica matemática contemporânea entende, nem, tão pouco, de afirmar que o método cartesiano só aceita como conhecimento científico o que for obtido através de axiomatização. Neste sentido rígido, nem mesmo a geometria de Euclides, do modo como ele a propôs, é axiomática. O que queremos é explicar, em linhas bem gerais, como se opera no método axiomático, utilizando a geometria como exemplo, e afirmar que o modo de conhecer e justificar, que Descartes propôs para a ciência, tem por modelo o método axiomático.

\section{DESCARTES E EUCLIDES À LUZ DE DEMÓCRITO: MÉTODO CIENTÍFICO E MÉTODO AXIOMÁTICO COMO EXPRESSÕES DO ATOMISMO}

Atomismo e método cartesiano estão intimamente relacionados. Por um lado a ontologia atomista sugere a separação entre sujeito e objeto, o que leva à busca ideal por conhecimento objetivo, livre das interferências do sujeito. Mas, como já apontamos, separação sujeito-objeto e a busca ideal de conhecimento objetivo são duas características fundamentais do método cartesiano. Por outro lado, vimos que o método cartesiano tem por modelo o método axiomático. Mas o que é o método axiomático senão uma espécie de atomismo no domínio do conhecimento? De que material teórico são feitas as coisas que podemos conhecer mediante o método axiomático? Elas são feitas dos conceitos fundamentais, dos 'elementos' de Euclides, de átomos indivisíveis, indestrutíveis, não

pontos finais como centro. (4) Todos os ângulos retos são congruentes. (5) Se duas linhas cruzam uma terceira de tal modo que a soma dos ângulos internos em um lado é menor que dois ângulos retos, então as duas linhas inevitavelmente cruzam-se neste lado se forem estendidas suficientemente. (Hofstadter, 1989, p.90)

Dialektiké. Ano 2, v. 2, out 2015, p. 03-37 | Revista de Filosofia 


\section{DURANTE, Daniel (2015)}

analisáveis, que se combinam para formar os conceitos mais complexos. De que é feito um triângulo senão de pontos e retas em um plano? Todos os objetos de que as teorias axiomáticas se ocupam são produzidos por combinação dos seus conceitos fundamentais, tanto quanto os corpos sensíveis, para Demócrito, são produzidos por combinações de átomos.

Esta ontologia atomista dos conceitos ilumina nossa racionalidade cientifica. Vejamos de que modo. Como são produzidas as explicações científicas? O que significa explicar cientificamente a proposição "esta ponte não suporta uma carga superior a 5.000 toneladas", ou a proposição “o chocolate é um alimento mais energético do que as verduras"? De acordo com o método cartesiano, explicar cientificamente estas proposições é mostrar que elas são consequência de alguma teoria científica, e isto é feito através da construção de uma prova, de uma demonstração da proposição a explicar, a partir dos axiomas (das leis) de alguma teoria. Dessa forma, para explicarmos alguma afirmação segundo o método cartesiano, temos, em primeiro lugar, que a dividir em tantas partes quanto possível para que possamos traduzi-la em termos dos átomos de alguma teoria. Assim, uma plantação de trigo da qual se queira saber a área deixa de ser uma plantação de trigo e se transforma em um conjunto de retas e pontos. Em segundo lugar, temos que ser capazes de reconstruir a afirmação traduzida a partir dos axiomas da teoria. Uma afirmação verdadeira (de acordo com a geometria) sobre a área desta plantação de trigo é obtida através de uma construção que parte dos axiomas da geometria e que expressa uma propriedade sobre o conjunto de retas e pontos que representa a plantação de trigo. Partindo-se dos axiomas, vai-se agregando proposições verdadeiras à teoria. Estas proposições agregadas são consequências imediatas dos axiomas-átomos e do já estabelecido. Prossegue-se neste processo até obter-se a afirmação que se queria explicar. A explicação é, pois, este conjunto organizado de proposições, composto de axiomas e proposições intermediárias deles obtidas. Podemos, então, entender as explicações científicas como uma construção de proposições, obtidas de um conjunto de axiomas e organizada de uma forma específica. Os "tijolos" desta construção são os conceitos fundamentais da teoria (os elementos no caso da geometria). Tal imagem é bastante semelhante à dos corpos sensíveis produzidos por um conjunto de átomos que se agregam e organizam de uma forma específica.

Assim, tanto do ponto de vista ontológico quanto do epistemológico, ou seja, tanto do ponto de vista da constituição dos objetos sobre os quais as teorias se referem, quanto do 


\section{DURANTE, Daniel (2015)}

ponto de vista do que se pode, teoricamente, conhecer sobre estes objetos, as teorias axiomáticas seguem o esquema geral do atomismo 5 . Não nos parece portanto exagero afirmar que Descartes, inspirado no modelo axiomático, tomou o atomismo de empréstimo quando propôs seu método científico, pois o atomismo e o método axiomático são como que duas expressões da mesma ideia. Ideia esta que representa um dos grandes legados dos gregos à nossa civilização.

Mas apesar de extremamente frutífera, apesar de ter propiciado todo o desenvolvimento científico e tecnológico que alcançamos, existem problemas com esta ideia. Problemas que, por estarem relacionados ao cerne do nosso modelo de representação do mundo, o atomismo, e do nosso modelo de explicação e atuação no mundo, o método científico, merecem reflexão.

Mas quais são estes problemas? Apenas a título de situar nossas preocupações e questionamentos, esboçaremos os aspectos mais gerais de alguns deles.

\section{CIÊNCIAS FORMAIS: INCOMPLETUDE E IMPOSSIBILIDADE DE OBJETIVIDADE}

Influenciados pelo sucesso do método axiomático na geometria e pelas diretrizes metodológicas cartesianas, os matemáticos, desde meados do século XIX, trabalhavam para obter uma caracterização axiomática geral de sua disciplina. Um dos grandes avanços obtidos neste esforço pelo rigor foi o que se chamou de aritmetização da matemática, que representou uma redefinição completa da matemática baseada apenas em conceitos da aritmética. (Kline, 1972, p.956) Todos os conceitos utilizados em todas as partes da matemática foram redefinidos utilizando-se apenas elementos da aritmética. Dessa forma, tanto quanto um número racional positivo, por exemplo, é definido como um par ordenado de números naturais, o numerador e o denominador da fração que o representa, todas as outras definiçõoes da matemática foram reduzidas a construções cujos elementos básicos eram aritméticos. Esta aritmetização da matemática foi muito importante, porque com essas novas e rigorosas definições, todas as obscuridades e imprecisões com respeito a complicadas partes da matemática superior, que incomodavam muitos matemáticos por esta época, agora estavam reduzidas a proposições claras e bem definidas sobre números naturais.

\footnotetext{
${ }^{5}$ Este modo de entender o conhecimento foi bastante desenvolvido por Bertrand Russell, na Filosofia do Atomismo Lógico (Russell, 1919)e pelo primeiro Wittgenstein no Tractatus Lógico-Filosófico (Wittgenstein, 1994).
} 


\section{DURANTE, Daniel (2015)}

O passo seguinte, e mais fundamental, seria realizar uma axiomatização da aritmética, o que exigia: (1) definir os elementos essenciais da teoria dos números naturais, (2) apresentar um conjunto de axiomas que descrevesse as suas propriedades fundamentais e (3) comprovar que este sistema axiomático seria capaz de provar todos os teoremas da aritmética e apenas eles. ${ }^{6}$ Os dois primeiros passos desta tarefa foram realizados, em 1889 , por Giuseppe Peano, um matemático italiano que apresentou um conjunto de três conceitos fundamentais e cinco axiomas que davam conta de demonstrar os principais teoremas da teoria dos números naturais conhecidos até então. ${ }^{7}$ Seria a vitória do método axiomático. Todas as complexas teorias matemáticas pareciam não exigir mais do que estes poucos conceitos e axiomas para serem propostas e demonstradas.

No entanto, um problema fundamental com o método axiomático foi melhor compreendido após Kurt Gödel demonstrar seu famoso Teorema da Incompletude. Em 1931, Gödel provou que existem certas sentenças da aritmética claramente reconhecidas como verdadeiras que, simplesmente, não podem ser demonstradas pelo método axiomático. Não só a axiomatização de Peano, mas nenhuma axiomatização possível seria capaz de demonstrar estas sentenças verdadeiras. ${ }^{8}$ Isto significa que o método axiomático é incompleto para expressar a aritmética, que sua estrutura racional é mais restrita que a racionalidade presente na aritmética. Tal fato enterrou todas as possibilidades de reduzir a matemática a uma simples teoria axiomática, evidenciando que há algo mais no raciocínio matemático do que simples manipulações sintáticas de leis sobre a teoria dos números naturais.

Se o método axiomático não se mostrou forte o suficiente para descrever a racionalidade nem dos elementos simples e ideais da aritmética, com boas razões deve-se supor que para as ciências empíricas, que envolvem conceitos muito mais complexos que os aritméticos, ele seja igualmente insuficiente. Além desta suposição, se seguirmos a indicação cartesiana, devemos admitir que os objetos complexos das ciências empíricas envolvem os objetos simples da aritmética em suas construções. Tal fato estende a incompletude da

\footnotetext{
${ }^{6}$ As propriedades descritas em (3) são conhecidas entre os lógicos como "correção" e "completude" do sistema axiomático.

${ }^{7}$ Os três conceitos fundamentais de Peano são: zero, número e sucessor. As suas cinco proposições primitivas são: (1) Zero é um número. (2) O sucessor de qualquer número é um número. (3) Não há dois números com o mesmo sucessor. (4) Zero não é o sucessor de nenhum número. (5) Qualquer propriedade que pertença a zero, e também ao sucessor de todo número que tenha a propriedade, pertence a todos os números. (Russell, 1960).

${ }^{8}$ Gödel provou, portanto, que é impossível completar o passo (3) acima, ou seja, não é possível obter um sistema axiomático completo para a aritmética. Sempre haverá sentenças aritméticas verdadeiras que não são possíveis de serem provadas por nenhum sistema axiomático.
} 


\section{DURANTE, Daniel (2015)}

aritmética para todas as ciências empíricas que admitam algum tipo de quantificação. Assim, tomar o método axiomático como modelo de explicação, como o fez Descartes e como o fazemos até hoje, é certamente limitador. Com o Teorema de Gödel aprendemos que é um erro acreditar que, de alguns conceitos básicos e algumas proposições evidentes sobre eles, conseguimos explicar tudo o que diz respeito a estes conceitos. ${ }^{9}$

Existe outro problema relacionado ao ideal de objetividade do conhecimento científico que o Teorema de Gödel nos ajuda a compreender. Para provar seu Teorema da Incompletude, Gödel primeiramente mostrou que é possível construir, em qualquer sistema axiomático para a aritmética, sentenças com dupla interpretação. Ele mostrou como interpretar as sentenças aritméticas, que expressam propriedades sobre os números naturais, como sendo sentenças que expressam propriedades sobre sentenças aritméticas. Assim, uma sentença aritmética A qualquer, além de expressar alguma propriedade dos números naturais, de acordo com a interpretação de Gödel expressa também alguma propriedade sobre outra sentença aritmética B. Utilizando-se deste artifício, Gödel criou sentenças auto-referentes, ou seja, sentenças que além de expressar alguma propriedade sobre números naturais, expressam também propriedades sobre si próprias. Mas, ao apontar duas interpretações possíveis para a mesma sentença, Gödel acabou mostrando que não temos meios de fixar, de antemão, a interpretação que queremos para uma sentença, nem mesmo em uma teoria aritmética formalizada. A escolha de qual interpretação dar a uma sentença é essencialmente uma propriedade do "sujeito" que escolhe. Se com os conceitos simples da aritmética já não é possível dirigir a interpretação, com mais razão ainda não é possível dirigir a interpretação quando se trabalha com os conceitos mais complexos que as ciências empíricas utilizam. Sendo assim, não se pode querer anular o sujeito de nossas explicações científicas. O ideal de objetividade científica, de explicar totalmente os fatos do mundo nos termos de suas próprias propriedades, sem interferência do sujeito, desconsiderando o modo pelo qual o sujeito é afetado por estes fatos, é uma ilusão. Sempre haverá um aspecto subjetivo na compreensão do

\footnotetext{
9 É importante deixar claro que estamos cometendo aqui um certo abuso interpretativo. As limitações que os teoremas da incompletude de Gödel impõem restringem-se a tipos de sistemas formais bastante específicos, os sistemas baseados na lógica clássica de primeira ordem. Em princípio nada impede que métodos formais nãoclássicos mais sofisticados pudessem nos dar teorias completas sobre a aritmética. No entanto, estes sistemas mais sofisticados muito provavelmente não seriam bons instrumentos para uma fundamentação da aritmética unanimemente aceitável, pois eles próprios envolveriam ferramentas aritméticas das quais pretendem ser fundamentação, caindo assim eu uma certa circularidade.
} 


\section{DURANTE, Daniel (2015)}

mundo que, pelo menos, afetará a escolha da interpretação que damos às sentenças das teorias científicas. $^{10}$

\section{FÍSICA QUÂNTICA E RELATIVIDADE: O ÁTOMO E A OBJETIVIDADE ATACADOS}

Além das ciências formais, o desenvolvimento da física também reforça estes problemas da racionalidade científica e aponta outros ainda. Tanto os desenvolvimentos da microfísica, na mecânica quântica, quanto os da macrofísica, na relatividade, mostraram que a nossa concepção de mundo parece funcionar apenas em, como diz Edgar Morin, uma onda média, um tapete voador flutuando entre as contradições de nossas descrições do infinitamente pequeno e do infinitamente grande (Morin, 1999, p.27).

No verão europeu de 1900, o físico alemão Max Plank convenceu-se de que a única maneira de explicar a mudança de coloração de corpos negros submetidos a altas temperaturas era admitir que a luz proveniente deste aquecimento fosse emitida em quantidades discretas, os quanta (Heisenberg, 1995, p.30). Tal descoberta contrariou não apenas as leis clássicas da radiação e calor, mas também toda a estrutura da própria física até então conhecida. De lá para cá, a microfísica abriu muitas outras portas, revelando-nos um universo microscópico totalmente novo e estranho, no qual não apenas as leis da física clássica, mas as leis da nossa própria racionalidade parecem não funcionar. Primeiramente o átomo, o elemento fundamental, simplesmente não se revela a nós. Há uma miríade de partículas e antipartículas, cada uma delas essencialmente fundamental, que se dividem na família dos quarks, que compõem os hadrons, que podem ser prótons e nêutrons, e na família dos léptons, que "vivem" fora do núcleo do átomo, cujo elétron é apenas um de seus membros. Além disso, tais partículas são, em sua maioria, extremamente instáveis, sendo que uma boa parte delas já se "extinguiu", tendo existido apenas nos primeiros trilionésimos de segundos após o bigbang, a explosão original que criou nosso universo (Fritzsch, 1990). Tudo muito diferente, portanto, dos átomos "permanentes e indivisíveis" idealizados por Demócrito.

Também a separação entre sujeito e objeto e o ideal de objetividade do conhecimento são atacados. As relações de incerteza de Heisenberg mostram como, na física quântica, o observador perturba a coisa observada. É impossível medir alguma propriedade física de um

\footnotetext{
${ }^{10}$ Para uma introdução clara e intuitiva ao Teorema de Gödel, ver (Hofstadter, 1989). Para os iniciados em matemática, o próprio artigo de Gödel, além de muitos outros históricos trabalhos de lógica matemática, podem ser encontrados na coletânea (Heijenoort, 1977).
}

Dialektiké. Ano 2, v. 2, out 2015, p. 03-37 | Revista de Filosofia 


\section{DURANTE, Daniel (2015)}

elétron sem modificar alguma outra, de tal forma que é impossível darmos alguma descrição completa das propriedades físicas de um elétron. Quando tentamos "olhar" para os elétrons em algum experimento, aproximando uma fonte de luz, eles se comportam como se fossem partículas, apresentando resultados não muito diferentes do que projéteis macroscópicos apresentariam. Se repetimos o mesmo experimento, sem "olharmos" para os elétrons, eles se comportam como se fossem ondas, apresentando resultados não muito diferentes dos que ondulações em uma superfície líquida apresentariam (Gilmore, 1998) e (Resnick; Eisberg, 1980). Sendo estes dois resultados distintos e incompatíveis entre si, não podemos conhecer objetivamente o comportamento dos elétrons, pois eles se comportam diferentemente, dependendo da maneira como nós, sujeitos, os encaramos. Assim, qualquer descrição sobre o comportamento de elétrons é, de certa forma, subjetiva.

Outro problema apontado pela microfísica diz respeito à inserção do acaso no conhecimento. Probabilidade e incerteza já não são encaradas apenas como limitações dos nossos procedimentos de medição, tendo o papel meramente epistemológico dado pela teoria dos erros. Quando Max Born descreveu os elétrons como “ondas de probabilidade", ele deu a estes conceitos um estatuto ontológico na caracterização do objeto de conhecimento científico. Há, neste caso, uma diferença fundamental. Quando consideramos o acaso apenas como produto de erros e limitações do nosso processo de medição, estamos admitindo que, em princípio, podemos eliminar este acaso e explicar exatamente como as coisas acontecem. No entanto, quando o acaso é ferramenta teórica da descrição de um objeto, estamos admitindo que nossa explicação não se fundamenta em ideias claras e distintas, mas sim em conceitos difusos, incertos, indistintos. Estamos assumindo, portanto, que o método cartesiano não funciona muito bem neste caso.

Ainda na microfísica, existem pares de entidades que se relacionam de uma tal maneira que, quando invertemos o sentido de rotação (spin) de um dos componentes do par, a rotação do outro também se inverte. A experiência de Aspect mostrou que, mesmo quando separamos cada um dos elementos destes pares no espaço, a mudança do sentido de rotação em um dos componentes continua provocando a mudança instantânea na rotação do outro, ainda que a distância entre eles seja grande. Mas a nossa maneira normal de entender interações em entidades separadas no espaço sugere que, para que um fenômeno que ocorre em uma entidade $\mathrm{A}$, situada em uma posição $\mathrm{X}$ do espaço, interfira de alguma forma em uma entidade B, situada em uma posição Y, algo, alguma forma de matéria ou energia, algum tipo 


\section{DURANTE, Daniel (2015)}

de informação deve ter sido transmitida de uma entidade para a outra e viajado entre as posições X e Y. Acontece que já sabemos, desde Einstein, que nada viaja mais rápido que a luz. Como a mudança no sentido da rotação de A provoca, instantaneamente, uma mudança no sentido da rotação de $\mathrm{B}$, independentemente da distância entre elas, então este tipo de relacionamento entre A e B simplesmente não se enquadra em qualquer tipo de explicação causal que conhecemos. ${ }^{11}$ Ele sugere que A e B, em algum sentido que desconhecemos, continuam unidas; que existe algum tipo de relação entre estas entidades físicas que está além do espaço e do tempo. De alguma forma, A e B, ainda que distantes, não são totalmente distintas e a nossa capacidade de distinguir e separar, base do método cartesiano de conhecer, simplesmente não funciona em todas as ocasiões. ${ }^{12}$

Quanto à macrofísica, a teoria da relatividade de Einstein uniu numa mesma entidade - o espaço-tempo quadridimensional - os conceitos até então heterogêneos de espaço e tempo. Mostrou que a matéria deforma o espaço e, mais de cem anos depois de Kant, proferiu mais um ataque à objetividade do conceito de tempo: corpos com velocidades diferentes experimentam diferentemente o tempo. Dessa forma, duas das principais ferramentas para a descrição objetiva dos fenômenos, o espaço e o tempo, não mais podem ser vistas como insuspeitas de "deformações" subjetivas, pois sujeitos em condições diferentes os percebem diferentemente. Einstein retirou-nos a possibilidade de encontrarmos uma estrutura universal sobre a qual podemos posicionar os fenômenos para dar-lhes descrições objetivas. (Pais, 1995)

Todos estes problemas, apenas superficialmente apontados aqui, e muitos outros que têm surgido nas mais diversas áreas do conhecimento, não são simples problemas científicos. Atacam questões que dizem respeito ao cerne dos nossos modelos de representação e explicação do mundo, exigindo-nos reflexão.

Segundo Edgar Morin,

já não há mais solo firme, a 'matéria' já não é a realidade maciça elementar e simples à qual se podia reduzir a physis. O espaço e o tempo não são mais

\footnotetext{
${ }^{11}$ Cabe esclarecer que a teoria de Newton admitia uma forma de interação deste tipo (a distância e imediata), afirmando que uma mudança na massa em um corpo mudaria "instantaneamente" a força de atração gravitacional nos corpos à sua volta, independentemente da distância. No entanto, este aspecto foi posteriormente esclarecido e enquadrado em padrões de explicação mais aceitáveis através da teoria do campo gravitacional.

12 Uma boa introdução, não técnica, porém bastante profunda, às principais ideias e questões filosóficas suscitadas pela física quântica é (Heisenberg, 1995). Uma abordagem tecnicamente mais profunda, porém filosoficamente mais pobre, pode ser encontrada em (Pais, 1995).
}

Dialektiké. Ano 2, v. 2, out 2015, p. 03-37 | Revista de Filosofia 
entidades absolutas e independentes. Já não há mais, não apenas, uma base empírica simples, mas uma base lógica simples (noções claras e distintas, realidade não ambivalente, não contraditória, estritamente determinada) para construir o substrato físico. Daí uma consequência capital: o simples (as categorias da física clássica que constituíam o modelo de qualquer ciência) não é mais o fundamento de todas as coisas, mas uma passagem, um momento entre complexidades. (Morin, 1990, pp.27-28)

A ideia fundamental do atomismo, de que toda a realidade material pode ser objetivamente explicada através de elementos simples, estáveis, separáveis, claramente distinguíveis, que se combinam e recombinam de forma controlada e previsível é profundamente atacada, internamente à ciência, pelo próprio desenvolvimento da física. Juntamente, a ideia subsidiária desta, de que a reconstrução cognitiva da realidade fornecida pelo conhecimento científico deve seguir os mesmos padrões, ou seja, a ideia fundamental do método axiomático, de que o conhecimento parte de elementos simples, auto-evidentes e se estrutura por encadeamento lógico e coerente destes elementos também é profundamente atacada pelos desenvolvimentos da lógica e da matemática. Estes não são problemas meramente científicos, são problemas metodológicos e epistemológicos graves que ultrapassam os limites das disciplinas onde foram encontrados, pois atingem o núcleo da nossa forma científica de entender e explicar a realidade.

\section{DA EPISTEMOLOGIA À ÉTICA: 'O LADO MAU' DA CIÊNCIA}

Mas, apesar de importantes e fundamentais, com exceção da experiência de Aspect, que foi realizada em 1983, os problemas aqui apontados já eram todos conhecidos nos anos 30 do século XX. No entanto, por serem problemas longínquos, no universo do infinitamente grande e do infinitamente pequeno, ou em regiões extremamente especializadas do raciocínio formal e abstrato, estes problemas (e muitos outros não apontados) ficaram mais ou menos adormecidos, enquanto a ciência e a tecnologia cresciam vertiginosamente. Foi preciso muito tempo para que começássemos a perceber que o desenvolvimento científico e tecnológico, além de não resolver questões sociais importantes, parecia agravá-las inclusive, além de criar problemas novos, tais como inúmeras catástrofes ambientais e a sempre presente ameaça de destruição global. É sobre a relação destes problemas com o nosso modo de fazer ciência, o nosso modo atomista de representar e explicar o mundo, que vamos agora refletir. 


\section{DURANTE, Daniel (2015)}

É inegável que a ciência e a tecnologia (tecnociência) vêm, há séculos, obtendo resultados fabulosos em nossa capacidade de compreender e atuar no mundo. Através de ambas domesticamos a energia nuclear, produzimos computadores com espantosa capacidade de processamento, instrumentos de comunicação à distância baratos e espantosamente eficientes e deciframos todo o código genético da espécie humana. Mas esta mesma tecnociência que avança indiferente a despeito dos problemas metodológicos e epistemológicos que apontamos, não apenas parece não nos ajudar a resolver os nossos principais problemas, com também parece contribuir para o agravamento de outros, conforme destacamos na introdução.

Estes traços negativos da ciência, no entanto, não costumam ser identificados como características intrínsecas do nosso modo de produzi-la. Os cientistas costumam se defenderse de tais aspectos negativos atribuindo a responsabilidade sobre eles exclusivamente ao mau uso que tem sido feito do conhecimento científico. O discurso hegemônico é o de que o conhecimento científico é neutro com relação a valores. Os cientistas desvendam aspectos objetivos da realidade e se suas descobertas são mal utilizadas por empresas e estados e terminam por causarem danos, isto não é visto como responsabilidade da ciência nem dos cientistas.

No entanto, uma questão fundamental que emerge do que temos discutido é a seguinte: estariam estes dois tipos de problemas (epistemológico-metodológicos e éticos) relacionados? Em outras palavras, estariam os problemas éticos da ciência, suas consequências nocivas, relacionados com os aspectos epistemológicos da explicação científica hegemonicamente aceita e utilizada? Seriam a busca do atomismo, a separação sujeito-objeto e a eliminação dos aspectos subjetivos das explicações científicas coresponsáveis pelos problemas que o conhecimento científico e tecnológico tem produzido e amplificado? Em caso afirmativo, que fazer? Seria possível repensar a ciência de modo que seu "lado mau" fosse minimizado? Como?

Há muitas maneiras de encararmos estas questões e de procurar-lhes explicações. Seguindo os passos de Edgar Morin e Hugh Lacey e mantendo a coerência com a abordagem que vincula o conhecimento com os projetos e interesses que o motivam, defenderemos que os problemas epistemológicos e éticos são, sim, fortemente relacionados, sendo este um pressuposto que assumimos e a partir do qual várias possibilidades de pesquisa se apresentam, tais como: (1) entender a maneira pela qual se dá esta relação a fim de esclarecer de que 


\section{DURANTE, Daniel (2015)}

forma as escolhas ontológicas e epistemológicas que historicamente a ciência foi adotando influenciaram no tipo de conhecimento produzido e em seus "efeitos nocivos"; (2) procurar novos modelos racionais de explicação, novas formas de organização da atividade científica; (3) procurar relações históricas entre a racionalidade científica vigente e certos interesses sociais das "classes" que defenderam e financiaram a ciência (tanto no passado como no presente); (4) buscar diretrizes para a atividade científica, tanto em seu nível cognitivo, quanto em seu nível de atividade coletiva e social, com objetivo de propor políticas de fomento que induzam uma produção científica menos "nociva" e mais voltada para a solução dos enormes problemas socioambientais atuais.

\section{DAS TEORIAS À SUPERESPECIALIZAÇÃO: NÃO HÁ CIÊNCIA UNIFICADA}

Buscando esclarecer as relações entre as questões epistemológicas e os problemas éticos da ciência, de modo a defender o pressuposto acima exposto, um importante aspecto a se considerar diz respeito à divisão disciplinar do conhecimento. $\mathrm{O}$ método cartesiano, modelado no método axiomático, tem como consequência o fechamento do conhecimento em teorias. Quando dividimos a realidade em busca das ideias claras e distintas, para, a partir destas, reconstruir e explicar o objeto, tendemos a explicar objetos semelhantes através das mesmas ideias iniciais, e objetos muito diferentes através de ideias iniciais diferentes. Ou seja, temos a tendência de construir teorias diversas, disciplinas diversas. Mas, quanto mais sabemos sobre o mundo, mais complexas se tornam nossas teorias e explicações, e mais se torna necessário separar e compartimentar a realidade em teorias e disciplinas inteligíveis, porém distintas. Acontece que vivemos uma verdadeira explosão de especialidades e disciplinas. Para se ter uma ideia, no já longínquo ano de 1987, estavam catalogadas 8.530 diferentes áreas de conhecimento sobre as quais se desenvolviam pesquisas. (Crane; Small, 1992, p.197 ) Em busca da exatidão e formalização, e das vantagens da divisão de trabalho que o desenvolvimento disciplinar da ciência propiciou, chegamos a este absurdo de fragmentação e superespecialização que nos deixa às portas de um neo-obscurantismo, muito bem apontado por Edgar Morin.

Parece que nos aproximamos de uma temível revolução na história do saber, em que ele, deixando de ser pensado, meditado, refletido e discutido por seres humanos, integrado na investigação individual de conhecimento e de sabedoria, se destina cada vez mais a ser acumulado em bancos de dados, 
para ser, depois, computado por instâncias manipuladoras (...) Não devemos eliminar a hipótese de um neo-obscurantismo generalizado, produzido pelo mesmo movimento das especializações, no qual o próprio especialista tornase ignorante de tudo aquilo que não concerne a sua disciplina e o nãoespecialista renuncia prematuramente a toda possibilidade de refletir sobre o mundo, a vida, a sociedade, deixando esse cuidado aos cientistas, que não têm tempo nem meios conceituais para tanto. Situação paradoxal, em que o desenvolvimento do conhecimento instaura a resignação à ignorância e o da ciência significa o crescimento da inconsciência. (Morin, 1999, p.17)

Um dos grandes problemas com a superespecialização e com a profusão de teorias múltiplas sobre partes cada vez mais específicas da realidade está no fato de que teorias axiomáticas distintas não são entidades que possam ser facilmente combinadas em uma superteoria. Teorias axiomáticas possuem a irritante propriedade de, quase sempre, quando combinadas com outras, terem como resultado uma teoria trivial, ou seja, uma teoria onde vale tudo, onde todas as sentenças são verdadeiras, onde tudo o que é possível dizer através dos conceitos fundamentais seja demonstrável e portanto 'verdadeiro'. É como, por exemplo, se qualquer sentença da geometria fosse demonstrável. Poderíamos, neste caso, provar que um ângulo reto é igual a um ângulo raso, ou que a soma dos ângulos internos de um triângulo é tanto igual a $275^{\circ}$ quanto é igual a $179^{\circ}$. Evidentemente, uma teoria onde tudo fosse verdade não teria qualquer valor enquanto conhecimento, uma vez que não explicaria as restrições que a realidade nos impõe e que vivenciamos a cada instante.

As diversas ciências, disciplinas e teorias científicas constituem diante de nós um quadro abrangente e heterogêneo de descrições e explicações que, apesar de 'funcionarem' isoladamente, quando as tomamos como um todo, não fornecem uma compreensão coerente da realidade. Tal conhecimento envolveria necessariamente diferentes abordagens disciplinares e diferentes teorias. Teria, portanto, muitos pontos contraditórios e, tomado como um todo, levaria certamente a uma teoria trivial. $\mathrm{O}$ modelo axiomático, que levou à ideia da separabilidade, de que devemos recortar o real para a partir de noções claras e distintas obter o conhecimento como uma reconstrução, produziu a superespecialização disciplinar que torna inviável a construção de um conhecimento científico global e coerente da realidade. Se a ciência produz especialistas, ela não produz generalistas. Mas a maioria dos nossos problemas mais graves não é disciplinar, não está no escopo de alguma disciplina científica. São problemas complexos, que exigem de nós respostas que não encontramos nas ciências. Onde procurar estas respostas? Como conciliar explicações científicas ultraespecializadas, muito úteis para manipulações pontuais, com os problemas globais complexos 


\section{DURANTE, Daniel (2015)}

que não se encerram exclusivamente em nenhuma destas especialidades, sendo muitos deles, inclusive, decorrentes das próprias manipulações tecnocientíficas?

A primeira ideia inevitável de uma resposta que apenas começa a ser esboçada é integração. Antes de propor a integração como 'remédio', é preciso admitir que o que une fundamentalmente os principais problemas que têm resistido às atuais as tentativas de solução é a ausência de uma abordagem integradora. É preciso admitir, como nos lembra Morin, que o progresso inédito dos conhecimentos científicos, desintegrados, caminha paralelo ao progresso múltiplo da ignorância sobre como integrá-los, e a ampliação dos poderes localizados da ciência é acompanhada pela impotência dos cientistas com respeito a esses mesmos poderes e pela sua aparente inadequação para solucionar nossos mais graves problemas, que são globalizados.

Propomos, pois, abordar o "lado mau" da ciência como fruto de um desequilíbrio entre a compreensão localizada e globalizada. Juntamente com a compreensão localizada, fechada, ultraespecializada que a ciência nos dá, é preciso acrescentar uma compreensão globalizada, que nos dê subsídios para perceber e promover a integração no mais amplo sentido. Atribuir o "lado mau" da ciência apenas ao seu mau uso político não ajuda a resolver o problema, pois representa uma nova atitude desintegradora, que separa a esfera pública, social e de reflexão de um lado, e a ciência objetiva e irreflexiva de outro.

\section{A VINGANÇA DO SUJEITO: INVISIBILIDADE MÚTUA ENTRE CIÊNCIA E ÉTICA}

Esta desagregação, no entanto, tem sido a tendência histórica. A separação entre sujeito e objeto operou a eliminação positiva do primeiro da ciência. Nos dizeres de Bachelard, a ciência foi, historicamente, "psicanalisada", a fim de ter suprimidos os caracteres subjetivos de suas explicações (Bachelard, 1996). Os objetos, existindo independentemente, devem ser explicados pela ciência sem apelo às 'deformações' subjetivas, depurados de todos os juízos de valores. Assim, o belo, o feio, o bem, o mal, enquanto conceitos subjetivos, juízos de valores, não fazem parte de nossas explicações científicas. Esta separação, sobre a qual já apresentamos inúmeros problemas epistemológicos, leva a outro problema, ainda mais grave que os anteriores. Leva a uma irresponsabilidade científica, a uma inconsciência científica, a uma incapacidade da própria ciência em refletir-se, em lidar com e controlar os seus subprodutos nocivos. Não há, na própria ciência, espaço para reflexão. A reflexão, esta 


\section{DURANTE, Daniel (2015)}

característica intrinsecamente subjetiva de se auto-referenciar, foi proibida à ciência cartesiana pela separação entre sujeito e objeto e pelo ideal de objetividade (Morin, 1990). Não é à toa que o Teorema de Gödel, que nos mostrou um aspecto limitador do método axiomático como modelo de cognição, tenha sido obtido através da introdução de autoreferência em sistemas axiomáticos. Aliás, desde 1903, quando Bertrand Russell apontou seu famoso paradoxo conjuntista, mostrando os efeitos catastróficos da auto-referência para a matemática e a lógica, que os cientistas destas áreas vêm se esforçando para eliminar qualquer possibilidade de auto-referência de suas teorias (Russell, 1960). Decorre que sem o sujeito não há auto-referência na ciência, sem auto-referência não há reflexão, sem reflexão não há consciência, sem consciência não há ética, sem ética não há responsabilidade.

Mas, como diz Edgar Morin,

banido da ciência, o sujeito desforra-se na moral, na metafísica, na ideologia. Ideologicamente, é o suporte do humanismo, religião do homem considerado como o sujeito reinante ou devendo reinar num mundo de objetos (para possuir, manipular, transformar). Moralmente, é a sede indispensável de qualquer ética. Metafisicamente, é a realidade última ou primeira que reenvia o objecto como um fantasma branco ou, melhor, um lamentável espelho de estruturas do nosso entendimento. (Morin, 1990, pp.59-60)

Assim, do mesmo modo que não há lugar para o sujeito, quando se busca o mundo objetivo pela ciência, também vemos, na história da filosofia, o objeto tornar-se um "fantasma", "um lamentável espelho de estruturas do nosso entendimento", quando, na filosofia moderna, o sujeito passou a ocupar o centro das atenções filosóficas. Assim, do mesmo modo que nossa ciência prescinde do sujeito e, por isso, torna-se irresponsável e inconsciente, nossa filosofia prescinde do objeto e também, de certa forma, torna-se irresponsável e impotente para lidar com os novos desafios que a manipulação da natureza pela ciência e tecnologia vêm produzindo.

Vemos, agora, como estamos imersos na separação e longe da integração. É por isso que soa estranho o pressuposto defendido no item 7 acima, de que os problemas epistemológicos e éticos da ciência sejam fortemente conectados. Isto porque, historicamente, não há espaço para o sujeito na ciência e, portanto, não há espaço para a ética no conhecimento científico. Do mesmo modo, há cada vez menos espaço para a ciência na ética, pois esta opera na esfera do sujeito, que lega aos objetos o papel secundário de "espelho de estruturas de nosso entendimento", ou seja, de características do próprio sujeito. 


\section{E OS INTERESSES DA CIÊNCIA, QUAIS SÃO?}

Mas apesar do estranhamento que a insistência em ligar os problemas epistemológicos e éticos da ciência provoca, justificamos esta posição através da abordagem construtivista: o conhecimento é uma reorganização das experiências do observador que dá sentido aos seus projetos, que responde aos seus interesses. Mas resta a questão: a que interesses a ciência moderna tem respondido? Qual é o "ponto de vista" que penetra dissimulado no conhecimento científico? Quando colocada de maneira mais branda, não perguntando por interesses, mas por propriedades fundamentais do conhecimento científico, a posição hegemônica que aparece ao longo da história da filosofia da ciência, desde Francis Bacon, é a de que a propriedade utilitária fundamental do conhecimento científico é fazer prognósticos: prever. Foi o filósofo Jürgen Habermas, no entanto, quem colocou a questão nos termos mais incisivos acima descritos. Ele relacionou a essência da ciência a um interesse e identificou tal interesse com a capacidade de prognosticar ( ${ }^{\text {Habermas, }} 1975$ a, ${ }^{\text {p. } 295-296)} .{ }^{13}$ Mas de que nos servem as previsões e prognósticos da ciência? Qual o seu sentido para nós? Habermas sustenta que podemos revelar o sentido destas previsões exclusivamente através da análise das regras metodológicas que os cientistas utilizam e aceitam na produção do conhecimento. Do ponto de vista teórico, estas regras permitem às proposições científicas apenas a forma de leis hipotéticas que estabelecem a "covariância de grandezas observáveis". ${ }^{14}$ Do ponto de vista empírico (da verificabilidade do conhecimento), é necessário que os termos das proposições científicas se enquadrem a este tipo de formulação teórica, não impedindo sua visualização, e também que sejam sensíveis à manipulação, para que a verificação seja possível. Se é verdade que os termos das proposições da ciência emergem dos fatos, também é verdade que eles são filtrados. Só nos interessam aqueles com capacidade para estruturar nossa experiência no âmbito da ação instrumental. Como bem aponta o filósofo da ciência Hugh Lacey, a metodologia cientifica vigente opera através de "estratégias de restrição e seleção" que, antes de nos dar uma informação objetiva sobre o

\footnotetext{
${ }^{13}$ Cabe acrescentar que Habermas não é um construtivista, mas antecipou e influenciou a abordagem destes através de suas reflexões sobre conhecimento e interesse.

${ }^{14}$ Uma lei de covariância entre duas grandezas observáveis A e B funcionará como um instrumento de previsão de uma delas através da observação da outra. Um exemplo simples de uma tal lei é a equação matemática $y=2 x$. Enquanto lei de covariância ela nos informa que sempre que $x$ varia uma unidade, $y$ varia duas e sempre que $y$
} 


\section{DURANTE, Daniel (2015)}

modo como o mundo é, nos dá, na verdade, respostas adequadas aos interesses da ação instrumental de fundamentam esta metodologia, ou seja, respostas que serão boas ferramentas para previsão, manipulação e controle.

Qual, então, é o sentido das previsões científicas que parece emergir destas regras metodológicas? É a ação instrumental, a manipulação, o controle. Da mesma forma que é através do controle e da manipulação que o conhecimento científico é empiricamente verificado, é para o controle e a manipulação que ele se volta enquanto produto. A suposta objetividade das proposições científicas não representa o acesso aos fatos em si, despidos de conotações subjetivas; representa apenas uma seleção criteriosa que reduz os aspectos subjetivos unicamente ao interesse de prever para manipular e controlar. Tal seleção é produzida pelas regras metodológicas, que exigem o enquadramento das proposições científicas à forma lógica das leis de covariância e a adequação de seus termos a grandezas com possibilidade de observação e manipulação (Lacey, 1998). O atomismo como modelo ontológico e o método axiomático como modelo epistemológico representam as duas ferramentas mais gerais que têm sido usadas para promover estes enquadramentos e adequações, respondendo assim aos interesses da ciência de previsão para manipulação e controle.

Se tratamos unificadamente os problemas epistemológicos e éticos, é porque admitimos que tanto a estrutura cognitiva mais geral da ciência é uma resposta racional a certos interesses subjetivos, quanto fica evidente, quando identificamos tais interesses com previsão, manipulação e controle, que seu 'lado mau' também é consequência deles. Ou seja, a concepção instrumental da ciência liga, definitivamente, sua epistemologia e sua ética.

\section{SE A CIÊNCIA NÃO RESOLVE NOSSOS PRINCIPAIS PROBLEMAS, QUE FAZER? IMPERATIVOS, POSSIBILIDADES E APOSTAS}

A ciência não resolve nossos principais problemas, porque eles não são problemas científicos; ou melhor, eles não são problemas disciplinares. Todos os problemas que conseguimos resolver com a ciência estão no âmbito de alguma disciplina científica, mas os problemas da fome, guerras, miséria, violência, injustiças sociais, e até mesmo os desequilíbrios ambientais, ameaças de extinção, degradação do meio ambiente,... não são

varia uma unidade, $x$ varia meia. Uma tal equação é um instrumento de previsão do que ocorrerá com $x$ caso observemos a variação de $y$ e vice-versa.

Dialektiké. Ano 2, v. 2, out 2015, p. 03-37 | Revista de Filosofia 


\section{DURANTE, Daniel (2015)}

problemas de física, química, matemática, geologia ou biologia. São problemas da humanidade, de como nos relacionamos uns com os outros e com o meio-ambiente. Sua solução exige mais do que a ciência pode nos dar, que resume-se à eficiência em prever, manipular e controlar. A solução de nossos principais problemas exige uma reaproximação entre ciência e filosofia. Exige que no interior de nossas práticas científicas haja também espaço para o sujeito, exige que ampliemos nossa estratégia metodológica materialista, que seleciona e restringe apenas o que é localmente e quantitativamente manipulável.

Ao aumentar nossos possibilidades de ação manipuladora e controladora sobre o mundo, a ciência tem propiciado fundamentação para todo o avanço cognitivo e tecnológico que temos experimentado, mas este avanço, conforme frisamos, é tendencioso para decisões sobre qual é a melhor forma de vivermos nossas vidas. Ele parte de uma escolha já feita e não admite divergências. A melhor forma de vivermos nossas vidas, de acordo com os valores embutidos na metodologia atualmente vigente na ciência é agirmos individualmente da maneira mais eficiente possível no que diz respeito à manipulação e o controle de aspectos materialistas da realidade.

No entanto, conforme a história tem nos mostrado, estes valores não tem sido suficientes para resolvermos nossos principais problemas. É preciso buscar a integração nos mais variados níveis. Como o fazer? É preciso quebrar esta camisa de força da separação entre sujeito e objeto, é preciso que busquemos alternativas ao nosso modo tradicional de representar e explicar o mundo. É preciso que nossa ciência não seja tão distante de nossa ética, que nossa reflexão sobre o mundo não seja feita sobre bases tão estranhas às bases que utilizamos em nossa explicação do mundo. É preciso que busquemos caminhos para uma ciência consciente, responsável, reflexiva, e que nossa ética leve em conta mais do que apenas o sujeito transcendental. É preciso que achemos espaço para a auto-referência em nossas explicações científicas. É preciso enfraquecer as exigências de certeza dessas explicações, que reconheçamos a enorme complexidade da realidade e mesmo assim continuemos a refletir e raciocinar sobre ela. É preciso que aprendamos a raciocinar também sobre bases incertas, que abandonemos a necessidade das ideias claras e distintas como ponto de partida, que aprendamos a lidar com as contradições. É preciso que as "interferências" subjetivas, as artes, as tradições, os juízos de valor, a ética não sejam tão estranhos à ciência quanto têm sido, e que a ciência não seja apenas este corpo tão fragmentado e especializado sobre o qual não se pode refletir ou discutir. 


\section{DURANTE, Daniel (2015)}

Não se trata, no entanto, de negar a ciência instituída nem, tão pouco, de legislar sobre o que pode ou não ser feito em ciência. Trata-se, sim, de reconhecer os diversos problemas epistemológicos e éticos relacionados ao conhecimento científico e de buscar-lhes uma solução integrada. Se há imperativos, eles não devem ser encarados como prescrições filosóficas, mas apenas como expressões dos compromissos implicados por esta busca de solução integrada. São apenas caminhos, possibilidades, apostas que ainda precisam mostrar o seu valor. Mas, se por um lado há séculos de tradição científica sendo questionados, por outro, além da urgência dos muitos problemas socioambientais à nossa volta, há também uma crescente desconfiança de cientistas, intelectuais, educadores, artistas e cidadãos em geral quanto aos poderes da ciência para resolvê-los. Há, além disso, muitos desenvolvimentos da própria ciência que, ainda isoladamente, cada um ao seu modo, vêm sugerindo outras estruturas para a racionalidade científica. Entre eles há os desenvolvimentos da Cibernética e da Teoria Geral dos Sistemas, iniciados por Ashby e Bertalanffy, respectivamente. Há os trabalhos de Ilya Prigogine, prêmio nobel de Química, sobre estruturas dissipativas, que introduzem a criação da ordem pela desordem. Há os trabalhos de Henry Atlan sobre a autoorganização do ser vivo e o seu princípio de ordem pelo ruído, o acaso organizador, com aplicações que vão desde a biologia celular até a informática. De fora das tradições científicas, há os esforços de Basarab Nicolescu para a implantação de uma transdisciplinaridade científica, que busca uma integração das diversas disciplinas entre si e com outras formas não científicas de conhecimento. Há os trabalhos de Edgar Morin que, de certa forma, conjugam esses diversos desenvolvimentos na teoria da complexidade, como um novo modelo para a racionalidade científica. De cunho mais filosófico há, entre muitas outras, a abordagem de Hugh Lacey, que também vincula a atividade científica e seus objetivos a valores sociais e defende que deve haver espaço para pesquisa científica motivada por outras perspectivas de valores além daquelas corporificadas nas estratégias metodológicas atuais. Há, no âmbito da tecnologia, a reflexão de Andrew Feenberg, que também defende uma forte vinculação da tecnologia com valores e aponta para a necessidade de uma apropriação democrática sobre os caminhos do desenvolvimento tecnológico. ${ }^{15}$

\footnotetext{
15 Algunas referências bibliográficas destes trabalhos são (Ashby, 1970), (Bertalanffy, 1977), (Prigogine; Stengers, 1979), (Atlan, 1972), (Nicolescu, 1999), (Morin, 1999), (Lacey, 1998) e (Feenberg, 2002).
} 


\section{COMPLEXIDADE, TRANSDISCIPLINARIDADE E O INTERESSE DA CIÊNCIA}

Enquanto tentativas de congregar estes esforços, de organizar as novas possibilidades que estes questionamentos sobre o conhecimento científico nos apresentam e de promover integração, começam a tomar forma duas ideias básicas, capturadas pelos conceitos de complexidade e transdisciplinaridade, respectivamente. A primeira delas representa a suposição de que a realidade pode ser mais complexa e interconectada do que nos é permitido compreender através do esquema conceitual que o atomismo impõe à ciência. A segunda procura dar uma resposta a esta complexidade e interconexão sugerindo que devemos conduzir as pesquisas científicas através de uma abordagem que integre ao máximo diferentes disciplinas, diferentes formas de conhecimento e diferentes aspectos da realidade.

Podemos identificar quatro características fundamentais na transdisciplinaridade que, inclusive, ajudam a compreender sua relação com a complexidade:

1. A transdisciplinaridade é orientada para a solução de problemas práticos, e não por questões teóricas inseridas nos corpos das disciplinas.

2. Impelida pela orientação a problemas a ir além das disciplinas, a transdisciplinaridade representa, fundamentalmente, a busca de maneiras de viabilizar a difícil integração de abordagens diversas. ${ }^{16}$

3. Esta busca de integração de abordagens sugere que a transdisciplinaridade parte de uma consideração holista do conhecimento. Longe das colorações místicas não acadêmicas deste termo, holismo é aqui usado no âmbito estrito da filosofia da ciência e da linguagem, como proposto por W.V. Orman Quine (Quine, 1951) e significa, basicamente, a suposição de que, no contexto das teorias científicas, não são as proposições ou teorias isoladas que são empiricamente testadas, mas sempre o nosso sistema de conhecimento como um todo que é confirmado ou não pela experiência. As proposições, teorias e disciplinas estão, pois, intrinsecamente ligadas em um teia que forma o nosso sistema de conhecimento.

4. O reconhecimento de uma ligação intrínseca entre os diversos campos do conhecimento faz que a abordagem voltada a solução de problemas, pretendida pela transdisciplinaridade, tenda a afastar-se das simplificações e modelos teóricos ideais

\footnotetext{
16 Muitos conceitos e sistematizações têm aparecido na literatura para caracterizar melhor esta posição: a transdisciplinaridade lida com boundary-objects (Star; Griesemer, 1989), realizando um boundary crossing (Klein, 1996), muitas vezes em uma traiding zone (Galison, 1997).
} 


\section{DURANTE, Daniel (2015)}

presentes no interior das disciplinas. Ao contrário, esta interligação entre diferentes áreas do conhecimento sugere que a própria realidade seja de certa forma interligada de um modo cuja complexidade escapa destes esquemas simplificadores. As explicações científicas devem, pois, supor esta interligação e, em vez de pautar-se por esquemas reducionistas, que tendem a minimizar as causas dos eventos estudados, devem reconhecer esta rede complexa de ligações e multicausalidades que compõem nosso sistema de conhecimento. Tal percurso corresponde a um projeto de alargamento da racionalidade científica que (Morin, 1990) chamou de pensamento complexo ou, simplesmente, complexidade.

Seguindo a orientação construtivista, no entanto, não vemos necessidade para apresentar uma justificativa ontológica sofisticada para as diretrizes metodológicas que a complexidade e a transdisciplinaridade apontam. Não é por causa da configuração última da realidade que devemos conhecê-la através de uma perspectiva holista. Uma justificativa pragmática para estas novas diretrizes deveria ser produzida relacionando os métodos e técnicas de pesquisa complexa e transdisciplinar com um novo interesse, um novo projeto, um novo conjunto de valores, um novo ponto de vista motivador da ciência. Não faremos aqui tal justificativa, que, no entanto, se faz necessária, mas está além dos objetivos deste ensaio. Apenas para indicar a sua direção poderíamos apontar, de forma bastante simplificada, que as diretrizes metodológicas da transdisciplinaridade e complexidade refletem a inclusão de um novo interesse na atividade científica. Antes de prognosticar para manipular e controlar, o interesse refletido pela transdisciplinaridade e complexidade seria o de mapear para equilibrar e dar autonomia. Ou seja, a abordagem holista, a busca pela integração de diferentes dimensões e diferentes abordagens disciplinares conduziria a um conhecimento com característica instrumental diversa do que normalmente obtemos através da ciência. Seria um conhecimento menos útil enquanto instrumento de manipulação e controle e mais útil enquanto instrumento de mapeamento e equilíbrio. Ao buscar a compreensão das múltiplas conexões, interligações e fluxos relacionados aos fenômenos perderíamos poder de atuação pontual sobre eles, no entanto ganharíamos compreensão sobre seu papel no todo, seu posicionamento na rede interligada de fatos que compõem a realidade. Isso representaria uma substituição do ideal de conhecimento enquanto guia sobre como atuar e intervir melhor na natureza, em nosso proveito, pelo ideal de conhecimento enquanto um mapa que posicionaria os diversos aspectos da natureza, mostrando como ela se auto-organiza e ensinando-nos, 


\section{DURANTE, Daniel (2015)}

inclusive, através de um entendimento de nosso papel nesta organização, como a natureza atua melhor em nós. É através deste projeto, deste interesse, que devemos procurar entender e avaliar as novas diretrizes da transdisciplinaridade e complexidade. ${ }^{17}$

Duas propostas surgem implícitas com este posicionamento metodológico: a de que a transdisciplinaridade e a complexidade refletem, de fato, este novo interesse científico; e a de que tal interesse e as atitudes que ele suscita são adequados para atacar os problemas da ciência que temos discutido. Ainda estamos longe, no entanto, de poder defendê-las satisfatoriamente. Transdisciplinaridade e complexidade são conceitos em construção, foco de controvérsias, o que tornam necessários esclarecimentos e acordos no que concerne às suas técnicas, aplicações, pressupostos e contexto. Qual a melhor maneira de integrar diferentes disciplinas? Qual o papel dos saberes não-científicos em uma abordagem transdisciplinar? Como tratar coerentemente a pluricausalidade e complexidade inerentes à rede do nosso sistema de conhecimento? Como lidar adequadamente com as contradições lógicas que a sobreposição de disciplinas e teorias diversas inevitavelmente provoca? De que forma o contexto social e político tem influenciado na emergência desta nova abordagem científica? Como têm se organizado e como poderiam melhor se organizar as instituições, para abrigar atividades de pesquisa transdisciplinar? Para qual tipo de problemas e questões a abordagem transdisciplinar e complexa representa um avanço, relativamente à abordagem científica disciplinar tradicional?

Estas são algumas das questões que se colocam como guias de investigações que, focadas na abordagem integrada dos aspectos epistemológicos, éticos, sociais e políticos da atividade científica, poderiam ter resultados importantes na proposição de novos métodos e formas de pesquisar, organizar, conceber e utilizar o conhecimento.

\footnotetext{
17 Dois comentários são pertinentes aqui. O primeiro é que o filósofo Hugh Lacey apresenta de modo relativamente detalhado um exemplo de como uma nova estratégia metodológica para a ciência já está mais ou menos em formação. Ele utiliza as pesquisas científicas vinculadas às práticas agroecológicas (agricultura orgânica) como caso paradigmático desta nova estratégia, e a compara com a estratégia materialista vigente, da ação instrumental, para a qual elegeu como caso paradigmático as pesquisas científicas voltadas às práticas biotecnológicas (agricultura transgênica) (Lacey, 2010). O segundo comentário é que, por justiça, vale notar que o próprio Habermas, que inspirou este relacionamento entre conhecimento e interesse, muito provavelmente não concordaria com a possibilidade de sugerir novos interesses para a ciência, conforme exposto em Habermas(1975b) em sua crítica a Marcuse. Tal posição nos parece devida a uma concepção rígida demais a respeito dos métodos racionais. Para Habermas, há apenas uma lógica e suas consequências são necessárias. No entanto, hoje sabemos que há infinitas lógicas com inúmeras sutilezas e especificidades. Tal variedade nos sugere uma maior flexibilidade racional e a possibilidade de propor alterações nos métodos atualmente utilizados nas ciências.
} 


\section{DURANTE, Daniel (2015)}

\section{PARA TERMINAR}

Nossa principal intenção com este ensaio foi a de apresentar uma reflexão bastante pessoal sobre o tema, que apresentasse e esclarecesse algumas possibilidades de pesquisa que nos interessam, mostrando que, apesar da enorme abrangência, elas estão relacionadas de forma coerente, inserindo-se em um programa. Programa este que se baseia em dois pressupostos fundamentais: o primeiro é o de que a magnífica ideia do atomismo, fundamento de nossa racionalidade científica atual, apesar de ter propiciado um espantoso avanço em nossa compreensão e capacidade de atuação no mundo, é insuficiente para resolver inúmeros dos problemas que a própria ciência nos coloca. O segundo, e mais fundamental, é o de admitir que a ciência é como é simplesmente porque nós a temos feito assim, não havendo qualquer necessidade imposta pela natureza ou pela estrutura de nossa racionalidade que nos impeça de ampliar e modificar nossa forma de conhecer cientificamente.

Mas que modificação é esta? Quais suas linhas gerais? Em que mesmo ela diverge da abordagem atualmente hegemônica? Poderíamos resumir a proposta afirmando que antes de mudar a natureza para que ela se adeque melhor aos nossos projetos, base da ação instrumental e dos interesses de previsão, manipulação e controle e fundamento da estratégia atual, que mudemos a nós mesmos para nos posicionarmos melhor na natureza. Não se trata de uma subordinação obediente aos desígnios superiores de uma natureza divinizada. Esta obediência não exigiria conhecimento e ciência, mas apenas resignação. Nossa proposta, no entanto, é para a ciência. Ainda que a melhor ciência que podemos fazer para responder aos interesse de prognosticar para controlar e manipular é a ciência que temos feito, sem ligarmos ciência e ética, sem nos questionarmos sobre os valores e interesses aos quais a ciência responde, não vamos conseguir usar a ciência para resolver os nossos principais problemas. Precisamos saber, aprender, pesquisar e, inclusive, atuar melhor na natureza. Mas ampliar nossa capacidade de controle e manipulação é apenas aumentar o poder ilegítimo sobre a natureza que a tecnociência atual inegavelmente nos dá. Mas poder Ilegítimo é violência. E o que precisamos é de conhecimento que legitime nosso poder sobre a natureza. Acontece que não há poder legítimo sem responsabilidade. Enquanto a natureza for apenas matéria-prima de nossos projetos, estaremos apenas exercendo nosso poder violento sobre ela e, ao mesmo tempo, permanentemente em conflito e risco. Quando percebermos que só poderemos melhorar tanto individualmente quanto coletivamente quando o foco central de nossas ações e conhecimento deixarem de ser o indivíduo e passarem a ser todo o sistema e suas 


\section{DURANTE, Daniel (2015)}

interconexões, talvez estejamos no caminho de solucionar os problemas relacionados à ciência. O tipo de conhecimento da natureza que sugiro para os cientistas investirem não é aquele que se torna instrumento de manipulação e controle da natureza, mas aquele que, ao conhecer a natureza, se torna instrumento de uma mudança nossa. Em nosso modo de vida individual e coletivo. Acontece a melhor maneira de se viver, individual e coletivamente, não costuma ser uma preocupação da ciência, como temos argumentado, mas da ética e da filosofia política. Então ciência, ética, política, filosofia, não podem caminhar de modo tão separado como têm caminhado. Ética precisa de ciência e ciência precisa de ética.

Não só a incapacidade da ciência em solucionar nossos mais importantes problemas mas também o próprio desenvolvimento disciplinar da ciência, com os problemas metodológicos e epistemológicos que apontamos aqui começam a nos mostrar que Demócrito não precisa estar sozinho como precursor dos fundamentos da racionalidade científica. Ele pode ter a ilustre companhia de Anaxágoras, um de seus antecessores entre os filósofos présocráticos, para quem não são os átomos permanentes e indivisíveis que fundamentam a realidade, mas sementes, partes que contém o todo. Dizia ele: “em todas as coisas há uma porção de todas as coisas".

\section{REFERÊNCIAS}

ASHBY, W. R. Uma introdução à cibernética. São Paulo: Perspectiva, 1970.

ATLAN, H. L'Organization biologique et la théorie de l'information. Paris: Hermann, 1972.

BACHELARD, G. A formação do espírito científico: contribuição para uma psicanálise do conhecimento. Rio de Janeiro: Contraponto, 1996.

BEN-DAVID, J. \& SUlliVAN, T. A. "Sociology of science." Annual Review of Sociology, PP. 203-222, 1975.

BERTALANFFY, L. Teoria geral dos sistemas. Petrópolis: Vozes, 1977.

COSTA, N. C. A. Sistemas Formais Inconsistentes. Curitiba: Ed. UFPR, 1993.

CRANE, D \& SMALL, H. "American Sociology since the Seventies: The Emerging Crisis in the Discipline". In: Sociology and its Publics: The Forms and Fates of Disciplinary

Organization, ed. Terence Halliday \& Morris Janowitz. Chicago: University of Chicago Press, 1992. 
DESCARTES, R. “Discurso do Método”. In: Descartes. São Paulo: Nova Cultural, 1996. (Os Pensadores)

FEENBERG, A. Transforming Technology: a critical theory revisited. New York: Oxford University Press, 2002.

FRITZSCH, H. Quarks; a matéria-prima deste mundo. Lisboa: Editorial Presença, 1990.

GALISON, P. Image and logic: a material culture of microphysics. The University of Chicago Press, 1997.

GILMORE, R. Alice no País do Quantum. Rio de Janeiro: Jorge Zahar, 1998.

HABERMAS, J. “Conhecimento e Interesse”. In: BENJAMIN, W. et al. Textos Escolhidos. São Paulo: Abril Cultural, 1975a. (Os Pensadores, 48) pp. 291 - 302.

. "Técnica e Ciência enquanto Ideologia ". In: BENJAMIN, W. et al. Textos

Escolhidos. São Paulo: Abril Cultural, 1975b. (Os Pensadores, 48) pp. 303 - 333.

HACKING, I. ¿La construcción social de qué? Barcelona, Espanha: Paidós, 2001.

HEIJENOORT, J. Van (org) From Frege to Gödel: a source book in mathematical logic. Cambridge, Mass.: Harvard University Press, 1977.

HEISEMBERG, W. Física \& filosofia. Brásilia: Ed. Unb, 1995.

HEMPEL, C. G. Filosofia da Ciência Natural. 3ed. Rio de Janeiro: Zahar, 1981.

HESS, D. J. Science Studies: an advanced introduction. New York: New York Univ. Press, 1997.

HOFSTADTER, D. R. Gödel, Escher, Bach: an eternal golden braid. New York: Vintage Books, 1979.

HORKHEIMER, M. "Teoria Tradicional e Teoria Crítica". In: BENJAMIN, W. et al. Textos Escolhidos. São Paulo: Abril Cultural, 1975. (Os Pensadores, 48) pp. 125 - 162.

KIRG, G. S. \& RAVEN, J. E. The presocratic philosophers. London: Cambridge Univ. Press, 1957.

KLINE, M. Mathematical Thought from Ancient to Modern Times. v III, Oxford Univ. Press, 1972.

KUHN, T. A estrutura das revoluções científicas. 5.ed. São Paulo: Perspectiva, 2000.

LACEY, H. Valores e Atividade Científica. São Paulo: Discurso Editorial, 1998. 
2004.

Is science value free?: values and scientific understanding. Psychology Press,

Valores e Atividade Científica 2. Editora 34, 2010.

LATOUR, B. Ciência em ação. Unesp, 2000.

A esperança de Pandora. Bauru: Edusc, 2001.

MERTON, R. K. "Os imperativos institucionais da ciência." A crítica da ciência: sociologia e ideologia da ciência 2, pp. 37-52, 1979.

MORIN, E. Ciência com consciência. Rio de Janeiro: Bertrand Brasil, 1990.

Introdução ao pensamento complexo. Lisboa: Instituto Piaget, 1999.

O Método 3: o conhecimento do conhecimento. Sulina, 1999 b.

O Método 2: a vida da vida. Porto Alegre: Sulina, 2001.

O Método I: a natureza da natureza. Porto Alegre: Sulina, 2005

NICOLESCU, B. O manifesto da transdisciplinaridade. São Paulo: Triom, 1999.

PAIS, A. Sutil é o Senhor: a ciência e a vida de Albert Einstein. Rio de Janeiro: Nova Fronteira, 1995.

PRIGOGINE, I. \& STENGERS, I. La Nouvelle Alliance. Métamorphose de la Science. Paris: Gallimard, 1979.

QUINE, W. V. O. “Two dogmas of empiricism”, Philosofical Review, v. 60, pp. 20-43, 1951.

RESNICK, R. \& EISBERG, R. M. Física Quântica. São Paulo: Campus, 1980.

RUSSELL, B. "The philosophy of logical atomism.", pp. 345-380, The Monist, 1919.

Introduction to mathematical philosophy. London: George Allen \& Unwin, 1960.

SHIVA, V. Monoculturas da mente: perspectivas da biodiversidade e da biotecnologia. Gaia, 2003.

Biopirataria: a pilhagem da natureza e do conhecimento. Vozes, 2001.

SOUZA, J. C. (org) Os pré-socráticos: fragmentos, doxografia e comentários. São Paulo:

Nova Cultural, 1996. (Os Pensadores, 1) 
STAR, S. L. \& GRIESEMER, J. R. "Institutional ecology, 'translations' and boundary objects: amateurs and the professionals in Berkeley's museum of vertebrate zoology, 1907 39”. Social studies of science, v. 19, pp. 387-420, 1989.

SUPPES, P. Studies in the Methodology and Foundations of Science. Reidel, 1969.

THOMPSON KLEIN, J. Crossing boundaries knoweledge, Disciplinarities and interdisciplinarities. The University Press of Virginia, 1996.

WITTGENSTEIN, L. Tractatus logico-philosophicus. Edusp, 1994. 